\title{
Experience of Radiology Technologists Performing Peripherally Inserted Central Catheters (PICC)
}

\author{
I. Aljediea ${ }^{1}$ \\ M. Alshehri ${ }^{1}$ \\ K. Alenazi ${ }^{1}$ \\ A. Memesh ${ }^{1}$ \\ ${ }^{1}$ Department of Interventional Radiology, Johns Hopkins Aramco
Healthcare, Dhahran, Saudi Arabia \\ Arab J Intervent Radiol 2021;5:88-92.
}

M. Fleet ${ }^{1}$

Address for correspondence Ibraheem Aljediea, Bsc, MHA, Johns Hopkins Aramco Healthcare, Dhahran, EAPA7910, DAMMAM, 34261, Saudi Arabia (e-mail: ksaibraheem@yahoo.com).

\author{
Abstract \\ Keywords \\ - atrial fibrillation PICC \\ - bedside PICC \\ - ECG-PICC \\ - electrocardiography \\ PICC \\ - interventional \\ radiology \\ technologists \\ - peripherally inserted \\ central catheter \\ - PICC line \\ - PICC privileging
}

Purpose We conducted this study to review our local experience of performing peripherally inserted central catheters by interventional radiology technologists.

Materials and Methods This is a retrospective study of peripherally inserted central catheters performed by interventional radiology technologists. These procedures were performed using ultrasound guidance for venous puncture and fluoroscopy or electrocardiography guidance followed by chest $\mathrm{X}$-ray to confirm tip location.

Results We reviewed all peripherally inserted central catheters performed in interventional radiology between May 2017 and July 2020. The review process included the success rate, number of venous puncture attempts, method of guidance, procedure time, fluoroscopy time, catheter duration to removal, and complications.

Conclusion Interventional radiology technologists can perform peripherally inserted central catheters safely with high success rate. Extending interventional radiology technologists' role to perform peripherally inserted central catheters allow interventional radiologists to do more complex procedures. This enhances the workflow, increases the interventional radiology team efficiency, and improves the waiting time.

\section{Introduction}

Peripherally inserted central catheters (PICC) provide reliable long-term central venous access. Advantages of PICC lines include lower infection rate, use for parenteral nutrition, antibiotic, chemotherapy, and reduction in the number of venous punctures needed during treatment. ${ }^{1,2}$ PICC insertion is performed by interventional radiologists, radiologist assistants, nurses, or radiology technologists. Nurses and radiology technologists can be trained to perform PICC insertions. ${ }^{2-8}$ In Saudi Arabia, interventional radiologists and nurses are the primary professions performing PICC insertions. ${ }^{4,5,8}$ Interventional radiology technologists in our hospital started training and proctorship program in 2017 to get competency in PICC line insertion. The study goal is to evaluate the performance and safety of PICC line insertions by interventional radiology technologists.

\section{Materials and Methods}

A training program to train interventional radiology technologists on performing PICC insertions was set up by the interventional radiology department in our hospital (Johns Hopkins Aramco Healthcare) in 2017. All required hospital ethical committee approvals were obtained. The training and proctorship were done by consultant interventional radiologists. Four interventional radiology technologists enrolled in the program with respective $5,9,19$, and 22 years of experience. published online December 22, 2021
DOI https://doi.org/ 10.1055/s-0041-1739303. ISSN 2542-7075. (c) 2021. The Pan Arab Interventional Radiology Society. All rights reserved.

This is an open access article published by Thieme under the terms of the Creative Commons Attribution-NonDerivative-NonCommercial-License, permitting copying and reproduction so long as the original work is given appropriate credit. Contents may not be used for commercial purposes, or adapted, remixed, transformed or built upon. (https://creativecommons.org/ licenses/by-nc-nd/4.0/)

Thieme Medical and Scientific Publishers Pvt. Ltd., A-12, 2nd Floor, Sector 2, Noida-201301 UP, India 


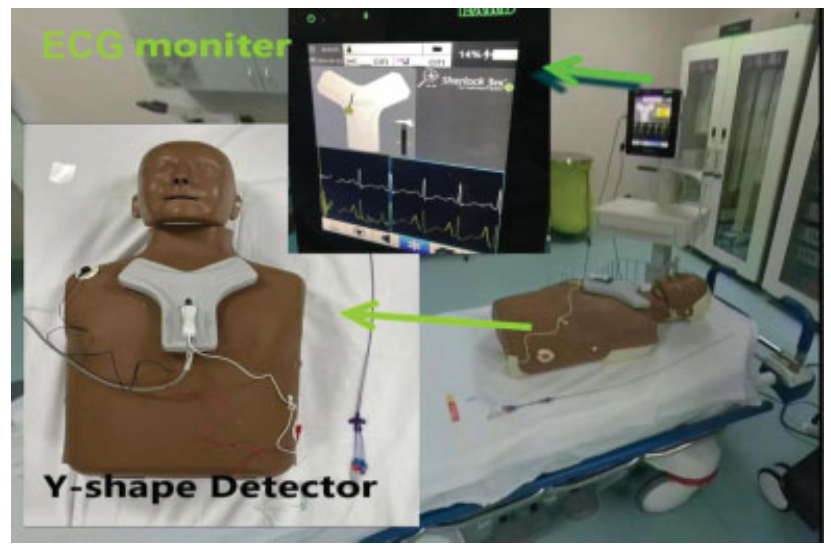

Fig. 1 Electrocardiogram (ECG)-guided peripherally inserted central catheter (PICC) line setup: the picture shows the setup for the electrocardiogram PICC. The Y-shape detector at the patient upper chest and the monitor show the lollipop when it is detected by the $Y$ shape detector.

The interventional radiology department is equipped with two rooms, one with C-arm and a second room dedicated for ultrasound-guided procedures. During the proctorship, interventional radiologists supervised each technologist in the first 30 procedures. The procedures are performed using electrocardiogram (ECG)-guided technique unless the patient's chart review showed potential central venous problem or if ECGguided PICC line kit was not available. The interventional radiologists were available in the department during all these procedures, usually working in the second room. The interventional technologists check the request to ensure adequate clinical indications, do the pre-procedure checklist, consent the patient, and perform the procedure. The interventional radiologist checks the postprocedure chest X-ray and reports the study in the patient chart within the electronic medical record.

All PICC lines inserted for adults and pediatrics were five French Power, double-lumen catheters, using Sherlock 3CG, ECG-guidance, and confirmation system (Bard access systems, Salt Lake City, Utah, United States). The ultrasound system is integrated with an ECG monitor and a Y-shaped tip tracking navigation system ( - Fig. 1). Venous punctures were done with real-time ultrasound freehand-guided technique using General Electric LOGIQ E9 (Diagnostx, Benjamin Center, Florida, United States). Fluoroscopy was performed using the Philips Allura FD20/20 C-Arm (Philips, Andover, Massachusetts, United States).

The PICC line insertion procedure starts with determination of the estimated catheter length by using the measurement ruler in the ECG-PICC kit, then performing ultrasound scan and selecting the target vein after applying a tourniquet on the arm. The tourniquet is released after selecting the target vein. The skin over the area of insertion is cleaned with chlorhexidine, the patient is draped with sterile cover, and the ultrasound probe is also covered with sterile plastic cover. The catheter is trimmed according to the estimated length, flushed with heparinized saline, and connected to the ECG detector of the navigation system ( - Fig. 2). The tourniquet is applied, local anesthesia $(5-10 \mathrm{~mL}$ lignocaine $1 \%$ ) is injected into the subcutaneous tissue under ultrasound guidance, and the target vein is punctured under ultrasound guidance, using Selinger technique. The tourniquet is released after venous puncture. A small skin incision is made, and the peel-away sheath is inserted over the guidewire after removal of the puncture needle. The dilator is removed, and the catheter is inserted inside the peel-away sheath until the lollipop indicating the catheter tip becomes visible on the screen of the ECG-guided machine. The catheter is advanced until the lollipop becomes green indicating the maximum peak of the p-wave. The peel-away sheath is removed, and the catheter is fixed and covered in sterile fashion.

\section{Results}

The interventional radiology technologists performed 570 PICC lines between May 2017 and July 2020 under the supervision of interventional radiologists. Three hundred and twenty-three (56.67\%) lines were inserted using ECG guidance, 243 (42.63\%) used fluoroscopy, four cases (0.7\%)

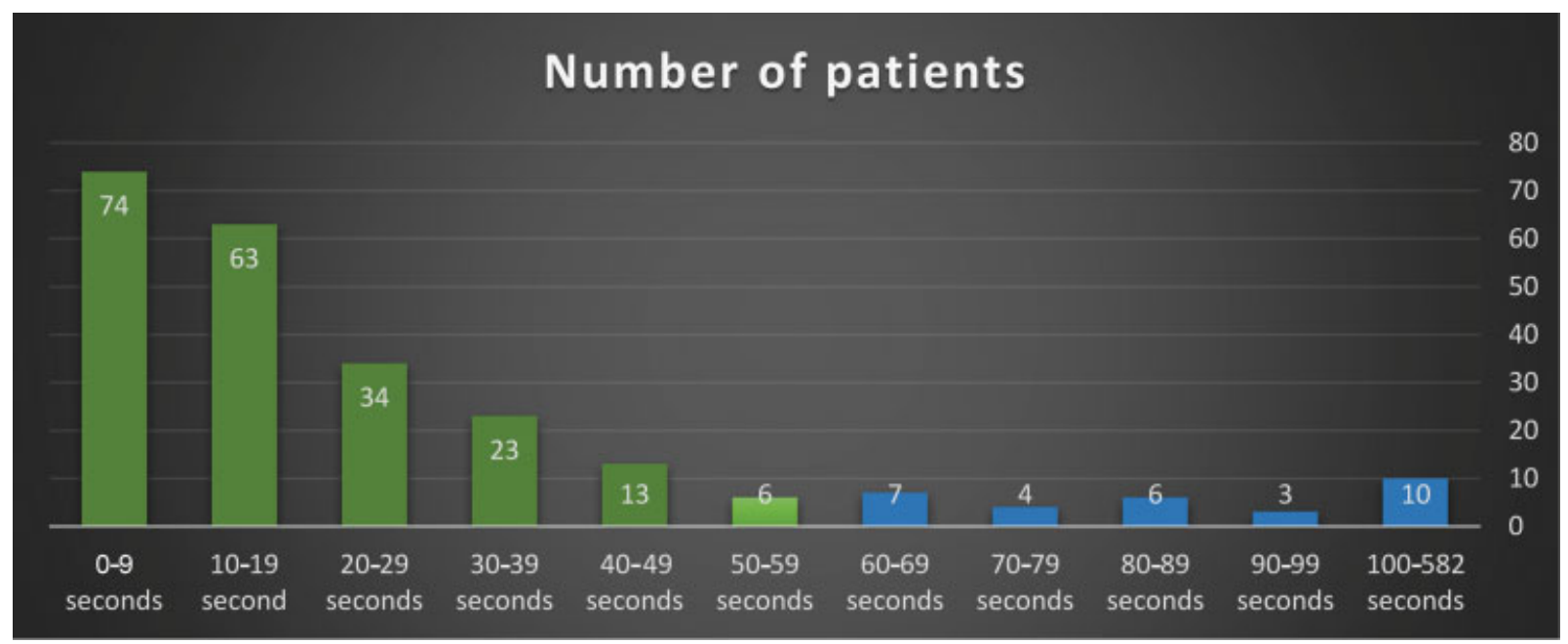

Fig. 2 Radiation time for 243 peripherally inserted central catheters performed fluoroguidance from May 2017 and July 2020: X-axis represents the radiation time; Y-axis represents the number of patients. 
Table 1 ECG-guided PICC versus fluoroscopy-guided PICC from May 2017 to July 2020

\begin{tabular}{|l|l|l|}
\hline Insertion method & Indication & $\begin{array}{l}\text { Number } \\
\text { of PICC }\end{array}$ \\
\hline ECG-guided & & 323 \\
\cline { 2 - 3 } & Prolonged antibiotics & 77 \\
\cline { 2 - 3 } & $\begin{array}{l}\text { Blood and FFP } \\
\text { transfusions }\end{array}$ & 1 \\
\cline { 2 - 3 } & Chemotherapy & 53 \\
\cline { 2 - 3 } & Difficult IV access & 125 \\
\cline { 2 - 3 } & TPN & 67 \\
\hline Fluoroscopy-guided & & 243 \\
\cline { 2 - 3 } & Prolonged antibiotics & 64 \\
\cline { 2 - 3 } & Chemotherapy & 25 \\
\cline { 2 - 3 } & Difficult IV access & 109 \\
\cline { 2 - 3 } & TPN & 45 \\
\cline { 2 - 3 } & Total & 566 \\
\hline
\end{tabular}

Abbreviations: ECG, electrocardiogram; FFP, fresh frozen plasma; IV, intravenous; PICC, peripherally inserted central catheter; TPN, total parenteral nutrition.

The table shows the number of patients versus the insertion method (ECG or fluoroscopy). Each method number of patients divided by the indication.

aborted because of patients' unstable condition. The age distribution was between 1.8 and 105 years. There was 288 (50.88\%) females and $282(49.82 \%)$ males. The indications for the inserted PICC lines are included in - Table 1. In 534 cases (94.35\%), the PICC lines were successfully inserted without difficulties, and no immediate complications occurred.

The target vein in the 566 PICCs was basilic in 369 cases (65.19\%), brachial in 163 cases (28.8\%), and cephalic in 34 cases (6.01\%). First venous puncture attempt was successful in 381 patients (67.31\%), second attempt in 50 cases (8.83\%), third attempt in 24 patients $(4.24 \%)$, and four or more attempts were made in 15 cases (2.65\%). In 96 patients (16.96\%), the number of attempts was not documented.

Two hundred and thirteen of the 243 (87.65\%) fluoroscopy-guided insertions were done with 59 seconds or less fluoroscopy time. Thirty cases (12.35\%) required fluoroscopy time between 60 and 582 seconds; these cases required catheter manipulation for central vein stenosis/occlusion (-Fig. 2).

In 36 patients (6.32\%), the technologists needed interventional radiologist assistance. Two cases had inadvertent brachial artery punctures; these were managed by manual compression over the brachial artery without consequences and the procedures continued after successful venous puncture. Forty-one patients with atrial fibrillation had ECGguided insertions, 39 patients had successful insertions, and two patients had line malposition; these were exchanged under fluoroscopy. There was no wire-loss, or catheter migration occurred ( $\mathbf{- T a b l e ~} \mathbf{2}$ ).

There was 24 pediatric PICC line insertions. Eighteen cases (75\%) were done with local anesthesia, and six patients (25\%) were performed under general anesthesia or deep sedation.

The procedure time (from time-out to sign-out) ranged between 3 and 90 minutes, as in - Table 3.

The waiting-time for PICC line insertion in the hospital improved after the radiology technologists started the service, which was 1 to 5 days; it became same-day service. The number of PICC line insertions procedures in the hospital has increased as shown in - Fig. 3 ; in 2020, the numbers are lower due to coronavirus disease 2019 restriction of elective services.

The lines remained in situ between 1 and 378 days with an average of 27.09 days. The treating physicians performed the PICC line removal. Three hundred eighty-eight lines (82.42\%) were removed after treatment completion. There was 16

Table 2 Number of cases requiring interventional radiologist's assistance

\begin{tabular}{|c|c|c|c|}
\hline Issues & Number of patients & \multicolumn{2}{|c|}{ Action } \\
\hline Arterial puncture & 2 & \multicolumn{2}{|c|}{$\begin{array}{l}\text { Manual compression was applied, and new venous puncture was } \\
\text { done successfully }\end{array}$} \\
\hline Venous puncture difficulty & 15 & \multicolumn{2}{|c|}{ The radiologist supervised the puncture technique } \\
\hline \multirow[t]{2}{*}{ Blocked vein } & \multirow[t]{2}{*}{10} & 8 & The other arm was used successfully \\
\hline & & 2 & The catheters were trimmed and left in peripheral vein \\
\hline Aborted & 4 & \multicolumn{2}{|c|}{ Unstable patients } \\
\hline Partial thrombosis/stenosis & 3 & \multicolumn{2}{|c|}{$\begin{array}{l}\text { The radiologists supervised advancing the catheter over hydro- } \\
\text { philic wire into SVC }\end{array}$} \\
\hline Malposition & 2 & \multicolumn{2}{|c|}{$\begin{array}{l}\text { These patients had atrial fibrillation, the lines were inserted using } \\
\text { ECG guidance, and these lines were exchanged under } \\
\text { fluoroscopy }\end{array}$} \\
\hline Total & 36 & & \\
\hline
\end{tabular}

Abbreviations: ECG, electrocardiogram SVC, superior vena cava.

The table shows the 36 case that required interventional radiology assistance. The table is divided into the issue/number of patients for each issue/the action for each group of patients with same issue. 
Table 3 Procedure time (time-out to sign-out)

\begin{tabular}{|l|l|l|l|l|l|l|l|l|l|}
\hline & $\begin{array}{l}3 \\
\text { minutes }\end{array}$ & $\begin{array}{l}3-5 \\
\text { minutes }\end{array}$ & $\begin{array}{l}5-10 \\
\text { minutes }\end{array}$ & $\begin{array}{l}10-15 \\
\text { minutes }\end{array}$ & $\begin{array}{l}15-20 \\
\text { minutes }\end{array}$ & $\begin{array}{l}20-30 \\
\text { minutes }\end{array}$ & $\begin{array}{l}30-40 \\
\text { minutes }\end{array}$ & $\begin{array}{l}90 \\
\text { minutes }\end{array}$ & $\begin{array}{l}\text { Total } \\
\text { patients }\end{array}$ \\
\hline Tech 1 & & & & 25 & 13 & & & 38 \\
\hline Tech 2 & 1 & 27 & 80 & 45 & 67 & 17 & 1 & & \\
\hline Tech 3 & & 1 & 1 & 39 & 33 & & & & 74 \\
\hline Tech 4 & & 3 & 68 & 46 & 81 & 15 & 2 & 1 & 216 \\
\hline & 1 & 31 & 149 & 155 & 194 & 32 & 3 & 1 & 566 \\
\hline
\end{tabular}

The table shows the time each technologist took for each insertion. The table is divided into a row for each technologist (and column for the time from 3-90 minutes) including the 36 cases that required interventional radiologists' assistance. The table also shows the total number for each technologist and total number of patients for each period.

PICC line infections (3.39\%). In 37 patients (7.84\%), the catheters were damaged or occluded. In 98 patients (17.31\%), the data are not available as these patients were transferred to other institutions.

\section{Discussion}

Training healthcare professionals to perform PICC insertions increase the procedure availability and reduces costs. ${ }^{2,3,7}$ One technologist and one nurse are required to perform the procedure. Interventional technologist's experience and skills in other interventional procedures are advantageous; this shortens the training time and learning curve. Direct access to interventional radiologists is essential for technologists performing PICC line insertions. ${ }^{3,7}$ Ten insertion procedures are the minimum mandatory number according to the American Registered Radiologists Assistance Board for certification and registration. ${ }^{9}$ In our institution, 30 cases supervised by the interventional radiologists were the mini- mum required as recommended by our institution's credentialing and privileging committee. PICC line insertion training programs should include relevant clinical teaching and practical skills training. ${ }^{7}$ Review of prior imaging such as chest X-rays and computed tomography allows detection of venous system abnormalities before the procedure. The preprocedure check includes reviewing the renal function and ECG. The technologists perform weekly huddles to discuss all performed PICC lines in the previous week to exchange experiences.

Fluoroscopy is used to take single image to visualize the catheter tip. Real-time fluoroscopy of the catheter was not utilized when advancing the line from the peripheral vein to superior vena cava. Trained nurses on fluoroscopy-guided PICC can perform the procedure with six or less seconds of fluoroscopy time. ${ }^{5}$ In bedside PICC, the catheter length can be predicted by using the patient's height. ${ }^{10}$ In pediatric patients aged between 0 and 203 months, measurement on prior chest X-ray in PACS system is accurate. ${ }^{11}$

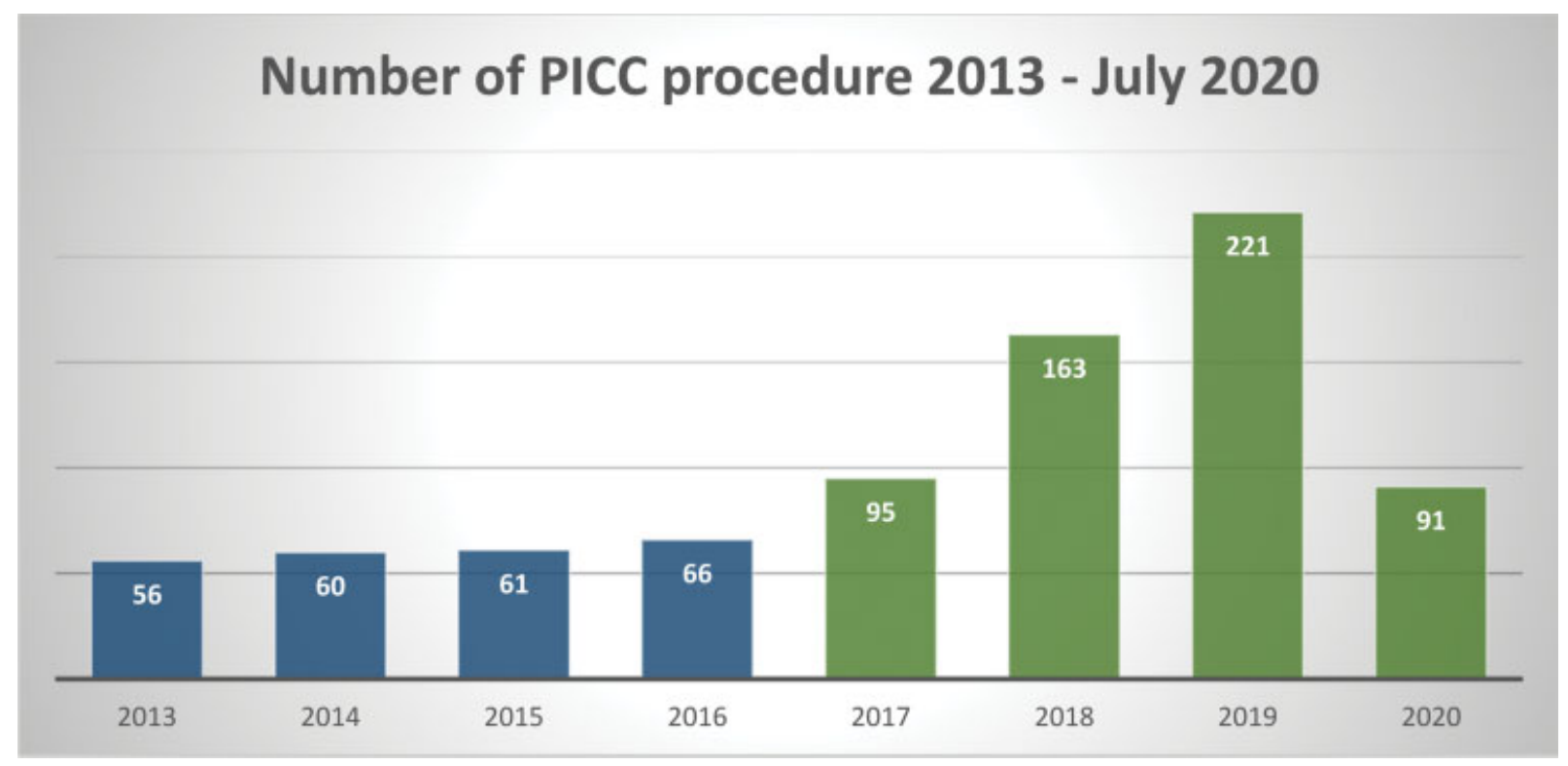

Fig. 3 Number of peripherally inserted central catheter (PICC) lines from 2013 to July 2020: X-axis represents the year; Y-axis represents the number of patients. 
The success rate of image-guided procedures is significantly higher than nonguided insertion. ${ }^{12,13}$ Nonguided PICC line insertion depends on using chin-down maneuver to avoid malposition of the catheter in the jugular vein. ECGguided insertion uses the magnetic $y$-shape device for navigation, and it depends on detecting the p-wave to position the catheter tip at the lower third of the superior vena cava. The navigation system detects heart rhythm from three leads (one around the right shoulder, the second at the iliac crest level, and the third from a stylet inside the PICC catheter). The Y-shaped magnetic navigation system is placed on the patient's chest at the level of the sternoclavicular joints to provide navigation for the catheter. The downward projection of the catheter on the Y-shape electromagnetic detector can indicate the proper location of the tip of the catheter. ECGguided technology allows performing PICC line insertion in the setting or semi-sitting positions when patients cannot lie down. The low incidence of malposition with ECG-guided PICC line insertion could potentially eliminate the need for chest X-ray post-procedure. In patients with atrial fibrillation or arrhythmia who have abnormal p-waves, ECG-guidance might not be reliable. ${ }^{8,10-12}$ Several previous studies excluded patients with abnormal heart rhythm from ECG-guided insertions. ${ }^{1,8,10-12,14,15}$ One study performed ECG-guided insertions on 118 atrial fibrillation patients; they relied on the amplitude of the f-wave. ${ }^{16}$ We performed ECG-guided insertions in 39 patients with atrial fibrillation, and we relied on the location and direction of movement of the tip of the sensor stylet inside the catheter. ECG-guided technology can be enhanced by integrating prior imaging with the navigation system during the procedure.

\section{Conclusion}

Our experience suggests that interventional radiology technologists can perform PICC line insertions with high success and low complication rates.

Conflict of Interest

None declared.

\section{References}

1 Yamagishi T, Ashida H, Igarashi T, et al. Clinical impact of the Sherlock 3CG® Tip Confirmation System for peripherally inserted central catheters. J Int Med Res 2018;46(12):5176-5182

2 Chan-Dinevski I, Annamalai G. Peripherally inserted central catheters (PICCs) at the bedside by X-ray technologists: a review of our experience. J Med Imaging Radiat Sci 2020;51(03): 373-378

3 Royce B. Use of C-arm fluoroscopy by nurses for placement of PICC lines. J Assoc Vasc Access 2009;14:138-141

4 Al-Tawfiq JA, Abed MS, Memish ZA. Peripherally inserted central catheter bloodstream infection surveillance rates in an acute care setting in Saudi Arabia. Ann Saudi Med 2012;32(02):169-173

5 Ismail A, AlDahr H, Tunio M. Experience of peripherally inserted central catheters in cancer patients at a cancer center of Saudi Arabia. Basic Research Journal of Medicine and Clinical Sciences. 2013;2:46

6 Shay W, Silva D, Mohabir H, Erinjeri J. The effect of radiologist assistants in an interventional radiology department. Radiol Technol 2017;88(03):333-338

7 Dabadie A, Soussan J, Mancini J, et al. Development and initial evaluation of a training program for peripherally inserted central catheter (PICC) placement for radiology residents and technicians. Diagn Interv Imaging 2016;97(09):877-882

8 Mohammed AT. Successful implementation of electrocardiographic-guided peripherally inserted central catheter placement by a nurse-lead peripherally inserted central catheter placement team. Arab J Intervent Radiol 2018;2(Suppl 1):1-33

9 American Registry of Radiologic Technologists. [Accessed July 16, 2020]; RRA Didactic and Clinical Portfolio Requirements - ARRT. https://www.arrt.org/docs/default-source/r.r.a/rra-applicationpacket-and-clinical-and-didactic-requirements-july-2018.pdf? sfvrsn=eeb04fc_18. Accessed Sep 15, 2021

10 Dale M, Higgins A, Carolan-Rees G. Sherlock 3CG( $\left.{ }^{\circledR}\right)$ Tip Confirmation System for placement of peripherally inserted central catheters: a NICE medical technology guidance. Appl Health Econ Health Policy 2016;14(01):41-49

11 Ramamurthi A, Chick JFB, Srinivasa RN, et al. Chest radiograph measurement technique facilitates accurate bedside peripherally inserted central catheter placement in children. Cardiovasc Intervent Radiol 2018;41(03):443-448

12 Tomaszewski KJ, Ferko N, Hollmann SS, et al. Time and resources of peripherally inserted central catheter insertion procedures: a comparison between blind insertion/chest X-ray and a real time tip navigation and confirmation system. Clinicoecon Outcomes Res 2017;9:115-125

13 Davis J, Kokotis K. A new perspective for PICC line insertions: cost effectiveness and outcomes associated with an independent PICC service. J Assoc Vasc Access 2004;9:93-98

14 Mack V, Nißler D, Kasikci D, Malouhi A, Aschenbach R, Teichgräber U. Magnetic tracking and electrocardiography-guided tip confirmation system versus fluoroscopy for placement of peripherally inserted central catheters: a randomized, noninferiority comparison. Cardiovasc Intervent Radiol 2020;43(12): 1891-1897

15 Moureau NL, Dennis GL, Ames E, Severe R. Electrocardiogram (EKG) guided peripherally inserted central catheters placement and tip position: results of a trial to replace radiological confirmation. JAVA 2010;15(01):8-14

16 Gao Y, Liu Y, Zhang H, Fang F, Song L. The safety and accuracy of ECG-guided PICC tip position verification applied in patients with atrial fibrillation. Ther Clin Risk Manag 2018;14:1075-1081 